Artigo recebido em 30/04/2015 Aprovado em 19/08/2015

Gilles Gauthier

Université de Laval gilles.gauthier@com.ulaval.ca Professor titular do Departamento de Informação e Comunicação da Université de Laval, Québec, Canadá.

Doutor em Filosofia pela Université du Québec à Trois-Rivières

Andriolli Costa (tradução) Universidade Federal do Rio Grande do Sul - UFRGS andriolli_costa@hotmail.com Doutorando em Comunicação e Informação pela UFRGS. Mestre em Jornalismo pela UFSC

\section{A verdade: visada obrigatória ao Jornalismo}

\author{
Gilles Gauthier
}

\section{Resumo}

Este trabalho reflete epistemologicamente e ontologicamente sobre o Jornalismo e sua ligação com conceitos filosóficos de verdade e realidade. Ligações estas que, atualmente, são tratadas com tabu e certo constrangimento. Para tanto, recorre à filosofia de John Searle e seus realismos metafísico (referente à realidade) e alético (referente à verdade) para pensar um realismo jornalístico, constituído desta dupla relação. Busca-se, neste artigo, expor como o reconhecimento da natureza construtivista do Jornalismo não implica a rejeição da existência de uma realidade bruta e nem da busca pela verdade. Estipula-se que a construção jornalística é feita a partir de uma realidade que lhe é anterior e que, visto que esta tem como objetivo reportar a realidade, que vise também à verdade.

\section{Palavras-chave:}

Jornalismo, Verdade, Realidade, Realismo, John Searle.

\begin{abstract}
This article proposes an epistemological and ontological reflection on Journalism and it's connections to the philosophic concepts of Truth and Reality - which, nowadays, are regarded with constraint as some kind of taboo in the communication field. For this purpose, the reflection is based on John Searle's philosophical though on the realism - both metaphysical (on reality) and alethic (on truth) - in order to propose a Journalistic Realism. In this article, we intend to expose how the acknowledge of Journalism's constructivist nature shouldn't lead to the rejection of the idea of a brute reality or of the search for the truth. We estipulate that the journalistic construction is made of an aprioristic reality and that, as it seeks to report reality, it should seek truth also.
\end{abstract}

\section{Keywords:}

Journalism, Truth, Reality, Realism, John Searle. 
Acredito que a questão de como pensar a respeito da verdade é crucialmente importante para problemáticas intelectuais em geral. É difícil enfatizar a quantidade de malefícios, especialmente neste século, que resultaram de confusões, assimilações falsas, e raciocínios levianos a respeito da verdade. (William P. Alston)

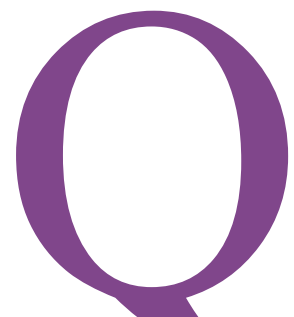

uero sustentar aqui que a verdade é um imperativo intrínseco ao Jornalismo. Mais precisamente, pretendo estabelecer que a possibilidade de produzir afirmações verdadeiras é um pressuposto da prática jornalística. Demonstrarei isso tomando como ponto de partida uma consideração bastante ingênua e aceita por todos: o fato de que o Jornalismo é uma atividade informativa. $\mathrm{O}$ reconhecimento da verdade como pressuposto do Jornalismo é uma proposição epistemológica. Ela estipula que o Jornalismo tem por função transmitir certo tipo de conhecimento, que é aquele relativo à atualidade. Esta proposição epistemológica implica também uma proposição ontológica: o reconhecimento da existência de uma realidade bruta, isto é, dada. A união dessas duas proposições forma uma posição filosófica geral: o realismo jornalístico. Formularei ainda duas outras afirmações mais precisas sobre este realismo. Por ora, gostaria de expor a consideração intuitiva sobre o Jornalismo que o funda e de formular algumas observações a respeito do contexto no qual estão presentes as discussões sobre as questões da verdade e da realidade no Jornalismo.

\section{A informação a priori do Jornalismo}

Independente da natureza mais determinada pela qual o Jornalismo é reconhecido, de uma concepção mais precisa ou definição mais apurada, a compreensão mais comum sobre o Jornalismo é aquela que lhe atribui função informativa. Intuitivamente, do ponto de vista mais frequente, Jornalismo é compartilhamento de informação. Esta é uma caraterística fundamental: suas possibilidades, as diferentes formas que pode tomar, as distintas práticas que pode resultar e os gêneros textuais que pode suscitar pouco importam. $\mathrm{O}$ Jornalismo provém de uma intenção informativa. Não há Jornalismo onde não haja o objetivo de informar. Não há dúvidas de que o Jornalismo raramente - ou mesmo nunca - é informação pura, mas sempre tem propósito informativo. Isso explica como o termo "informação" adquiriu sentido de sinônimo de "jornalismo" e é em virtude deste sentido que a expressão "as informações" pode ser usada para designar as matérias jornalísticas ou, ainda mais concretamente, as notícias.

A versão mais corrente sobre o objetivo das informações no Jornalismo é de afirmar que sua função consiste em relatar ou prestar contas com a atualidade. Da forma como considero, tal função informativa tem status de postulado. Vou assumi-la sem buscar demonstrá-la. Peço que o leitor endosse-a também. Minha pretensão é demonstrar que a admissão da "informação a priori" implica o reconhecimento de que o Jornalismo está sujeito à produção de afirmações verdadeiras e que tem como objeto uma realidade bruta. Procurarei estabelecer que aquele que admite que o Jornalismo tem um objetivo informativo está logicamente comprometido a considerar 
que este é a pesquisa da verdade sujeita à realidade.

A única maneira de evitar esta conclusão de duas partes é rejeitar a informação a priori do Jornalismo. No entanto, aquele que o quiser fazer será condenado a não poder conceber o Jornalismo, ou ao menos de imaginar um "jornalismo" outro que não aquele que consideramos normalmente. Recusar ou ignorar esta intenção informativa é negar as próprias possibilidades do Jornalismo, e do que nós consideramos hoje como sendo Jornalismo.

O postulado informativo vem do senso comum. Isto é intuitivamente óbvio. De um ponto de vista perfeitamente ingênuo, o leitor do jornal, o telespectador ou o ouvinte de rádio tem como expectativa que nós prestemos conta dos eventos do dia. Da mesma forma, os jornalistas atribuem a si próprios esta função fundamental de relatar a atualidade. Eles o fazem mesmo normalmente, aplicando certo recuo reflexivo. Diversas cartas e declarações de princípios das associações profissionais de jornalistas colocam esta função no topo da lista de obrigações do meio. Para citar apenas um exemplo, o Guia Deontológico da Federação Profissional dos Jornalistas do Quebec abre com a seguinte declaração: "O papel fundamental dos jornalistas é relatar fielmente, analisar e comentar, se necessário, os fatos que permitem a seus concidadãos melhor conhecer e melhor compreender o mundo em que vivem".

\section{O construtivismo ambiente}

De certa forma, as relações necessárias do Jornalismo com a verdade e a realidade são tão intuitivas quanto a informação a priori que lhes serve de base. Assim como atribui ao Jornalismo uma função de informar, o senso comum considera que ele está fortemente ligado à verdade e à realidade. Pode parecer bastante absurdo que os pressupostos relativos à verdade e à realidade sejam os objetos de uma demonstração como a que eu pretendo seguir. Do ponto de vista mais natural que podemos ter sobre o Jornalismo, não seria uma obra de grande originalidade.

Por que, então, se preocupar em articular e argumentar sobre uma posição realista no Jornalismo? Estabelecer as relações do Jornalismo com a verdade e a realidade não é forçar uma porta aberta, haja vista que, apesar de sua natureza óbvia, hoje es-

\section{A verdade e a}

\section{realidade são tão intuitivas quanto a informação para o Jornalismo}

tas estão sendo fortemente contestadas. A questão levantada, no entanto, não é menos complexa. Ela assegura, entre outras coisas, que os conceitos de verdade e de realidade tornaram-se tabus. Ou pelo menos que passaram a ter um uso quase que envergonhado. Quando os utilizamos, são frequentemente citados para que sejam limpos de seu sentido literal ou distanciados de seus significados usuais. Até certo ponto, minha defesa do realismo no Jornalismo consiste em contribuir para a reabilitação do senso comum sobre a verdade e a realidade no Jornalismo.

Os jornalistas que, no entanto, reconhecem a informação a priori em sua prática profissional, se recusam a admitir também a sua subordinação a verdade e a realida-
${ }^{1}$ Esta é a minha ênfase. Relatar os fatos não é a única função atribuida ao jornalismo. Mas ela é logicamente anterior a de analisar e comentar. Além disso, quero estabelecer aqui como pressuposto ao declarar que o papel principal dos jornalistas é relatar "fielmente" os fatos, a afirmação de uma informação a priori do jornalismo e o reconhecimento de sua subordinação a um imperativo de verdade. Disponivel em: <http://www.fpjq. org $>$. 
${ }^{2}$ Procurei em outros trabalhos (GAUTHIER, 1991 e 1993) mostrar que o questionamento da objetividade jornalística contemporânea não é probatório em qualquer das perspectivas a partir do qual é conduzida (epistemológica, ontológica, psicológica, pragmática, ética ou ideológica) e que o debate sobre a objetividade jornalística exige um esclarecimento de definição prévio que nunca é considerado.

3 "O fato bruto não é a origem do trabalho jornalístico, ele é o resultado: aquilo que se apresenta finalmente como um fato na redação da notícia resulta de toda uma série de construções" (DELFORCE, 1996, p. 21). simplesmente não existe um "mundo real" sobre o qual nós podemos tentar ser objetivos" (DERVILLE, 1999, p.53).

${ }^{4}$ Delforce recusa a possibilidade de que a imprensa seja um "reflexo preciso da realidade" (p. 22); Derville, que o trabalho dos jornalistas consista em "descrever [a realidade] com fidelidade" ( $p$.

${ }^{5}$ Este construtivismo parece ser a ideologia epistemológica dominante no início do século

21. É a vulgata pré ou acrítica no centro da sensibilidade intelectual contemporânea.

Deve fazer história e identificar suas diversas fontes. Entre elas figuram sem dúvida, sem que os autores mencionados tenham eles próprios aderido a ideologia construtivista, os trabalhos de Piaget em psicologia e em teoria do conhecimento, Berger e Luckman em sociologia do conhecimento, Kuhn e Feyerabend em história das ciências e, mais recentemente,

Bruno Latour em sociologia das ciências. Também fazem parte da nebulosa inspiradora do construtivismo a "arqueologia do saber" de Foucault e o desconstrutivismo de Derridá. Habermas, ao menos o de Conhecimento e Interesse, também pode ser visto como um precursor do construtivismo. De forma mais ampla e mais confusa, algumas abordagens, tais como o pragmatismo e a pragmática, bem como alguns rótulos sobre diversas posições teóricas mais ou menos aparentadas como o "pósmodernismo" são também, por sua vez, tributos e contribuições ao construtivismo. Na ciência da informação e comunicação, o inspirador do construtivismo, mais influente é provavelmente Paul Watzlawick. de. De fato, os jornalistas estão hoje em situação de duplo constrangimento. Se por um lado, em razão do postulado informativo próprio do Jornalismo e da relação com a verdade e a realidade, podem melhor legitimar sua função social e marcar com clareza a sua especificidade em relação aos demais profissionais da comunicação pública, por outro relutam em reivindicá-la, em parte por não desejarem se limitar a um papel de mera testemunha - o que, ao que parece, os impediria de assumir totalmente sua "responsabilidade social". Uma indicação muito clara deste mal-estar é a rejeição de alguns de nós da norma da objetividade em favor de uma regra de honestidade, sem que os dois termos estejam definidos ou mesmo claramente distintos um do outro ${ }^{2}$.

Deve-se dizer também que predomina atualmente no Jornalismo, assim como na comunicação como um todo - e, de maneira ainda mais abrangente, em toda a realidade social -, um ponto de vista construtivista. Este construtivismo resulta em exageros na ideia óbvia da construção da realidade social. Como as instituições e outras formações sociais não são naturais, mas sim criações humanas, infere-se que estas não possuem relação nenhuma com a realidade não construída e nem com a verdade. Assim, o construtivismo no Jornalismo tem como ponto de partida sua inquestionável natureza construída. Esta, ao mesmo tempo em que é em si uma prática social cujo objeto fundamental seja a realidade social, afirma que o Jornalismo não procede ${ }^{3}$ de dados anteriores e que não tem a função, ou a capacidade, de dar conta fielmente da realidade . Tentei em outras oportunidades (GAUTHIER, 2003) mostrar que, ainda que o Jornalismo e a totalidade da realidade social se- jam construídos, não se pode concluir que a construção jornalística seja feita a partir do nada e que ela seja exemplo de todo relato da realidade bruta. Ainda que evidente, a natureza construída da realidade social e do Jornalismo deve ser analisada e descrita.

O construtivismo culmina em uma forma extrema quando a ideia de construção da realidade social torna-se a da construção social da realidade. Não é concebido somente que a realidade social seja construída, mas, mais radicalmente, que não há outra realidade que não aquela construída socialmente 5 . Menciono em Gauthier (2004a) problemas, no meu ponto de vista insuperáveis, colocados na ideia da construção social da realidade aplicada ao Jornalismo.

Questões sobre realidade e verdade são umas das mais antigas da filosofia. Eles levaram, ao longo da história, a debates sobre questões mais específicas sobre a qual colidiram doutrinas tão díspares que vão além da tradicional oposição entre realismo e idealismo. No entanto, também foi possível para Alston (2002 e 2000) propor-se a diferenciar dois tipos de realismo contemporâneos os quais se opõe igualmente aos antirrealismos. Alston distingue um realismo metafísico, sobre a questão da realidade, e um realismo alético, sobre a da verdade. O próprio Alston é um defensor dos dois realismos.

$\mathrm{O}$ realismo metafísico gira em torno da ideia central de que existe uma realidade independente dos seres humanos. O antirrealismo metafísico, do qual Putnam (1990 e 1987) e Rorty (1991 e 1979) são os maiores representantes, considera, ao contrário, que nada existe fora das representações e conceituações feitas pelos seres humanos. 
O realismo alético baseia-se, por outro lado, em torno de uma concepção de que a verdade é uma proposição (no sentido lógico da palavra) e, por extensão, uma crença e um enunciado são verdadeiros se e somente se o que se afirma ser o caso é realmente o caso. Ao realismo alético opõe-se um antirrealismo "epistemológico", o qual Dummett (1991 e 1978) e Putnam (1981 e 1978) estão entre os principais defensores. Nele, a verdade de uma proposição não é relativa a sua relação com uma situação, mas sim à racionalidade e a coerência do sistema de pensamento ou discurso em que a proposição tem lugar.

Embora o construtivismo não se apresente, estritamente falando, como uma doutrina filosófica e embora as teorias filosóficas antirrealistas não sejam essencialmente centradas em torno das ideias da construção da realidade social e da construção social da realidade, é claro que o construtivismo dá relevância ao antirrealismo. Isto é verdade para todos os campos da atividade humana em que a abordagem construtivista é adotada, incluindo o Jornalismo. Por consequência, não é possível tratar o construtivismo no Jornalismo e as questões que se apresentam sobre verdade e realidade sem estacar na oposição entre as filosofias realistas e antirrealistas. A posição sobre o Jornalismo que vou discutir agora é realista no sentido de ambos os realismos, metafísico e alético, e está enraizada na filosofia de John Searle (1998, 1995 e 1979).

\section{O realismo jornalístico}

O realismo jornalístico do qual sou defensor pode ser expresso por meio de dois enunciados relativos a sua relação com a realidade e a sua relação com a verdade. Aqui estão dois enunciados na formulação do que é especificado da relação entre realismo e a natureza construída do Jornalismo. O primeiro enunciado trata da realidade: 1) Existe uma realidade independente do Jornalismo e é sobre esta realidade independente que trata, em última instância, o Jornalismo. É a partir desta realidade independente que provêm a construção jornalística. O segundo enunciado diz respeito à verdade. 2) O Jornalismo consiste na produção de asserções verdadeiras sobre esta realidade independente. A atribuição de valor de verdade é atividade anterior à construção jornalística.

Os dois enunciados são aqui expostos seguindo a sua ordem lógica. Formalmente, a realidade antecede a verdade. Deve-se primeiramente reconhecer a realidade para, em seguida, considerar possível a produção de asserções verdadeiras sobre ela. O reconhecimento de uma realidade pré-jornalística bruta é assim necessariamente prévia ao relato do Jornalismo sobre a verdade. De um ponto de vista puramente lógico, o enunciado do realismo relativo à realidade é mais primitivo que aquele relativo à verdade.

No entanto, a demonstração de apoio dos dois enunciados a partir da informação a priori do Jornalismo segue a ordem inversa. É a produção de asserções verdadeiras no Jornalismo que é dedutível da premissa de sua função informativa. Isso não implica a relação do Jornalismo com a verdade. Assim como a verdade possui a realidade como lógica anterior, a produção de asserções verdadeiras em Jornalismo possui em si um pressuposto: o de que ele trata de uma realidade independente. É esta dependência formal que é ressaltada no início do texto. Quando se afirma a posição epistemológica de estabelecer a verdade como pressuposto do Jornalismo, 
implica-se a posição ontológica de postular a existência de uma realidade bruta. Os dois enunciados do realismo serão apoiados na ordem heurística e não na ordem lógica.

\section{A verdade no Jornalismo}

$\mathrm{O}$ enunciado relativo à verdade do realismo jornalístico afirma que o Jornalismo consiste em produzir asserções verdadei-

${ }^{6}$ Os quatro outros tipos de atos de fala são os atos "diretivos", cujo objetivo é levar o interlocutor a executar uma ação, os atos "compromissivo", cujo objetivo é comprometer o ouvinte a completar uma ação, os atos "expressivos" cuja finalidade é a de expressar um estado psicológico e os atos "declarativos" com o objetivo de criar uma situação em virtude de sua enunciação

${ }^{7}$ Por comparação, os atos diretivos e compromissivos são a direção do ajuste da linguagem: é a realidade que se encaixa ou não a seu conteúdo. Por consequência, eles não têm valor de Verdade e sua realização acontece sob uma avaliação diferente. Por exemplo, não faz sentido dizer que uma ordem ou promessa é verdadeira ou falsa.

Diríamos, no entanto, que uma ordem foi ou não foi executada. dependendo se a pessoa a quem se dirigiu fez ou deixou de fazer a ação que se comprometeu a realizar

${ }^{8} \mathrm{Na}$ chamada do jornal La Presse de segunda-feira, 11 de agosto de 2003 ras. O alcance preciso desta proposição será discutido mais tarde. Deve-se, primeiramente, compará-lo com a informação a priori do Jornalismo. Esta última propõe que o Jornalismo tem por objetivo fundamental informar ou, como normalmente se diz, de relatar a atualidade. Decorre deste pressuposto da informação a priori que o Jornalismo é um lugar de produção de asserções verdadeiras.

A demonstração feita aqui é sustentada na teoria dos atos de fala de Searle. Este identifica cinco tipos principais de atos de fala. Fica claro que a função ou objetivo da informação cai inteiramente dentro da categoria de atos assertivos, cuja finalidade é representar um estado de coisas ${ }^{6}$. Atos de fala como afirmar, formular hipóteses, deduzir e concluir são exemplos de atos assertivos: todos eles tratam, em termos específicos e nas modalidades próprias de cada um, de segmentos da realidade. $\mathrm{O}$ ato de informar no sentido jornalístico do termo é também um ato assertivo. Ele é usado para explicar estados de coisas cuja característica é ser uma novidade relativa e de interesse público.

Uma das características distintas essenciais dos atos de fala assertivos é a sua direção de ajuste linguagem-mundo. Eles são os únicos relacionados ao universo extra-discursivo, tratado de forma que o conteúdo é que deve se adaptar ao estado de coisas abordado. Conforme seja ou não o caso, conforme um ato assertivo apresentado (de acordo com seus procedimentos) represente ou não uma situação, sua execução será bem ou malsucedida. Para avaliar o sucesso ou o fracasso dos atos assertivos, nós os atribuímos valor de verdade. Assim, dizemos que uma afirmação, uma dedução ou uma informação é verdadeira se a afirmação, dedução ou informação tratar de uma situação real do mundo, e que ela é falsa no caso contrário. Informar, como os outros atos assertivos, é uma atividade que é concomitante com um valor de verdade ${ }^{7}$. A informação, produzida ou resultante desta atividade, é também por extensão verdadeira ou falsa.

Na medida em que, como propõe a informação a priori, a informação seja inerente ao Jornalismo, como uma função ou objetivo, este é também dependente dos valores de verdade. É isso que, naturalmente, é expresso pelo senso comum quando uma notícia é qualificada como verdadeira ou falsa. Consideremos um exemplo real: a notícia expressa pelo título "A maioria dos moradores do Quebec apoiam a ideia de uma carteira de identidade obrigatória"8. $\mathrm{O}$ ato de informar foi realizado pela demonstração, pois é do tipo assertivo e, assim, munido de uma direção de ajuste linguagem-mundo, possui valor de verdade. $\mathrm{O}$ ato em si, o enunciado e a notícia são verdadeiros (se efetivamente os moradores do Quebec apoiarem a carteira de identidade obrigatória).

Mesmo assim, a rigor, a informação é uma questão de valor de verdade e, portanto, englobando igualmente tanto falso quanto verdadeiro, o Jornalismo está sujeito apenas à verdade. $\mathrm{Na}$ apreensão mais natural que temos da imprensa, é de fato uma exigência colocada de maneira prá- 
tica e normativa relativa aquilo que é e ao que não é. Espera-se normalmente da informação jornalística que esta relate a atualidade que acontece e não aquela que não acontece. Por consequência, é perfeitamente justificado dizer que são as informações a priori que estão sujeitas ao Jornalismo para a produção de asserções verdadeiras ${ }^{9}$.

Sendo este o caso, também se deve especificar a natureza da verdade jornalística. Os conceitos de verdade e de verdadeiro experimentados ao longo do tempo adquiriram de certa forma uma forte conotação especulativa. Assim, eles são muitas vezes utilizados para designar não apenas um conhecimento fundamentado, mas também a precisão de uma convicção mais ou menos pessoal, um princípio de sabedoria, "valores" como a franqueza, sinceridade, autenticidade e até mesmo a realidade escondida nas suas dimensões ou pelo menos não aparente. É também, normalmente devido a estes significados especulativos, que o relato jornalístico da verdade é negado.

Como incluído no enunciado relativo à verdade do Jornalismo, as noções de verdade e verdadeiro têm um sentido essencialmente de ordem técnica: eles servem apenas para qualificar a relação que certos enunciados afirmam manter com aquilo que abordam. Este sentido técnico leva a uma concepção de correspondência com a verdade. Searle apresenta esta ideia de verdade-correspondência nos seguintes termos: "A afirmação é verdadeira se e somente se ela corresponde aos fatos" (1998, p. 255). Quase que completamente, a concepção de correspondência de Searle é equivalente a concepção alética de Alston ${ }^{10}$, segundo o qual "uma declaração [...] é verdadeira se e somente se o que ex- pressa como sendo o caso for realmente o caso" (1996, p. 5).

Em sua interpretação da teoria da verdade-correspondência, Searle deixa claro que não esconde nenhum impacto isomórfico. Para ele, dizer que um enunciado usado para realizar um ato de fala assertivo é verdadeiro não significa dizer que ele é um espelho da realidade que representa. É, mais uma vez tecnicamente, constatar que o enunciado é bem-sucedido ao representar a realidade do fato que ocorreu efetivamente tal como indica o enunciado.

Qual é o escopo desta posição epistemológica que afirma que o Jornalismo está sujeito à verdade? O que queremos dizer, especificamente, quando afirmamos que o Jornalismo consiste em produzir asser-

\section{A verdade é uma exigência no Jornalismo}

ções verdadeiras? Lembremos primeiro de que esta é uma implicação da informação a priori. $\mathrm{O}$ enunciado relativo à verdade do realismo jornalístico não consiste nem em uma declaração de princípios, nem em uma tese em sua própria justificação. É totalmente sobre o reconhecimento de que o Jornalismo exerce uma função ou persegue um objetivo de informar. $\mathrm{O}$ enunciado que afirma que há, no Jornalismo, produção de asserções está assim limitado somente ao Jornalismo informativo ou somente a parte do Jornalismo que consiste em informar, brevemente, apenas as notícias. Não se aplica ao Jornalismo de opinião ou ainda às análises e comentários
${ }^{9}$ Incidentalmente, o falso pode ser tecnicamente definido pelo verdadeiro (e vice-versa). Isto é o que muitas vezes é feito no jornalismo: quando uma notícia afirma que uma situação não é aquela que se apresenta.

${ }^{10}$ Alston considera que sua concepção alética da verdade é minimalista em relação à teoria da verdadecorrespondência que, ainda assim, não envolve necessariamente a sua opinião, embora admita que geralmente são bastante consistentes 
jornalísticos. A verdade é uma exigência localizada do Jornalismo; ela está circunscrita somente à natureza informativa. $\mathrm{Na}$ medida, no entanto, que desejarmos fazer depender o Jornalismo de opinião do Jornalismo informativo, assim como a análise e o comentário da notícia, devemos admitir que a verdade se coloca como uma necessidade básica do Jornalismo.

Além disso, inferir a partir do comunicacional a priori que o Jornalismo está sujeito à verdade não é, evidentemente, afirmar que a prática jornalística é sempre, de fato, determinada pela verdade. A produção de asserções verdadeiras no Jornalismo, tal como apresentadas aqui, é uma exigência lógica do Jornalismo e não uma constatação. Um requisito lógico que não é afetado pelos fatos onde, empiricamente falando, parece que o Jornalismo produz afirmações falsas muito mais que verdadeiras.

$\mathrm{O}$ enunciado relativo à verdade do realismo jornalístico é assim uma parte normativa. Ela incute no Jornalismo, em virtude da informação a priori, a tarefa de produzir asserções verdadeiras. Deste modo, contribui para um critério de avaliação do Jornalismo: permite distinguir a "boa" informação jornalística da "má" informação jornalística ao delimitar à primeira apenas as notícias verdadeiras e à segunda apenas as notícias falsas. Incidentalmente, a recusa em admitir a verdade como uma necessidade do Jornalismo

${ }^{11}$ Timisoara é a Capital do condado de Timis, na Romênia. No final de 1989, foi palco de protestos anticomunistas que tomaram todo o país, ato que foi vastamente coberto pelo jornalismo estadunidense resulta na incapacidade de distinguir as ocorrências ou manifestações adequadas e inadequadas. Da mesma forma com que aquele que rejeita a informação a priori do Jornalismo se inibe de concebê-lo adequadamente, aquele que nega que este é lugar de produção de asserções verdadeiras se condena a não poder avaliá-lo. Isso por que lhe é atribuído um dever de verdade, explicitamente ou não, que faz com que seja possível considerar as falhas e os erros do Jornalismo. Não é possível pensar os excessos de Timisoara ${ }^{11}$ e outros sem reconhecer a submissão do Jornalismo à verdade.

\section{A realidade no Jornalismo}

A informação a priori faz da verdade um pressuposto lógico do Jornalismo. Mas a possibilidade da produção de asserções verdadeiras é, de maneira geral, a ideia de que a informação é uma questão de valor de verdade possui em si mesma outro pressuposto: o da existência de uma realidade dada e, portanto, não construída. A verdade implica a realidade. Se somos levados a considerar que o Jornalismo está, por causa da informação a priori, sujeito a busca da verdade, somos fatalmente levados a reconhecer que existe uma realidade independente do Jornalismo a partir da qual ele constrói. Para colocar no jargão filosófico, o realismo alético implica um realismo metafísico: para considerar que a verdade nos enunciados assertivos dependa de sua correspondência aos fatos, deve-se admitir que estes fatos existem independente dos enunciados.

Searle, já mencionado anteriormente, é um dos principais filósofos contemporâneos defensores do realismo metafísico. Mais precisamente, ele defende a ideia de um "realismo externo", que afirma a existência de uma realidade independente de qualquer forma de representação humana. Para sustentar sua posição, ele desenvolveu uma série de argumentos que, para alguns, aplica-se particularmente à comunicação e ao Jornalismo, mesmo que o próprio Searle faça essa ligação explicitamente.

Provavelmente como o antirrealismo 
parece ser dominante hoje em dia, Searle tanto ataca quanto defende o realismo. Ele analisa os principais argumentos contra a existência de uma realidade bruta, especialmente o da relatividade conceitual, que é certamente o argumento mais frequentemente utilizado para afirmar, do ponto de vista construtivista, que o Jornalismo não está relacionado com a existência de algo anterior. A relatividade conceitual é a tese, bastante justa, que diz existir uma pluralidade de sistemas de representação diferentes para dar conta da mesma realidade. A relatividade conceitual está ancorada neste outro argumento, também justificado, de que os seres humanos não podem apreender a realidade a qual representam.

A relatividade conceitual postula que a representação não é única, mas sim que há uma diversidade de arranjos ou composições de representações para representar a mesma realidade. A relatividade conceitual implica que os diferentes sistemas de representação são convencionais e, portanto, arbitrários. Como escreve Searle: “O mundo está dividido da maneira que nós o dividimos, e se estamos inclinados a pensar que nossa maneira de dividi-lo é boa, ou é de uma forma ou de outra inevitável, podemos sempre imaginar sistemas de classificação opostos" (1998, p. 205-206).

No entanto, a realidade conceitual não implica o antirrealismo. Na verdade, não é devido ao fato de que a realidade pode ser representada de diversas maneiras que ela não existe. Não é por que o mundo nos é acessível por meio de diferentes sistemas de representação eventualmente divergentes que este não é independente de suas representações. A relatividade conceitual e o realismo não são, portanto, contraditórios: são duas frentes perfeitamente compatíveis. O fato que nossa apreensão do mundo requer a representação e que diversos sistemas distintos de representação podem ser elaborados para dar conta da mesma realidade não significa que este mundo não existe. Searle sustenta que, de fato, o relativismo conceitual é mais conciliável com o realismo do que com o antirrealismo. Segundo ele, conceber que diferentes sistemas de representação descrevem a mesma realidade implica aceitar que esta realidade existe.

Sem ser assim denominada, a realidade conceitual é o argumento mais frequentemente citado para sustentar que não há uma realidade anterior ao Jornalismo e que este é, assim, pura construção. Em sua versão mais comum (embora haja outras) os argumentos são os mesmos. O mesmo evento pode ser relatado de diferentes maneiras; mesmo quando estamos cientes dos pontos de vista opostos. Os jornalistas não registram a realidade; eles preparam descrições particulares em função de suas preferências subjetivas, de sua orientação ideológica e, mais tecnicamente, da seleção que fazem de certos elementos da situação.

Por consequência, não há uma realidade dada; os jornalistas estabelecem representações distintas daquilo que pode ser erroneamente considerado como realidade. Este argumento, como o da relatividade conceitual como um todo, é inválido. $\mathrm{O}$ fato de que podemos dar conta de um mesmo evento seguindo leituras diferentes ou mesmo divergentes não implica de modo algum que o evento não existe. A possibilidade de relatos diferentes e mesmo rivais é, de qualquer forma, compatível com a existência do que percebemos. A pluralidade de descrições jornalísticas do mesmo evento tende, ao contrário, ao reconhecimento da realidade: se diferentes interpre- 
tações são possíveis, é por que existe algo para interpretar.

Searle, na verdade, não tem a pretensão de fornecer evidências para a realidade externa. Não lhe parece possível conduzir uma demonstração convincente da existência de uma realidade exterior independente das representações humanas, assim como também não o é, evidentemente, estabelecer a sua não-existência. Segundo ele, o realismo não é uma tese ou mesmo uma hipótese, mas, fundamentalmente, a própria condição de formulação de teses e hipóteses. Para ele, a existência da realidade bruta deve ser encarada por qualquer pessoa que recuse o solipsismo. Uma vez que admito não ser a única coisa existente, devo aceitar o realismo. A realidade bruta é um requisito para qualquer pessoa que queira admitir a existência do outro, e, portanto, da realidade social, assim como da possibilidade de conhecê-la.

Essa ideia de realismo como pressuposto Searle apresenta na forma de um argumento transcendental que a torna uma condição da comunicação humana:

(...) nós tentamos efetivamente nos comunicar uns com os outros ao fazer certos tipos de enunciados em uma linguagem pública (...) há uma maneira normal para entender [esses] enunciados (...) e quando realizam atos de linguagem numa linguagem pública, os falantes tipicamente tentam chegar a um entendimento normal. Para uma grande classe (...) de enunciados, uma condição de in-

${ }^{12}$ Conhecido como "construcionismo social”, na versão francesa de $A$ Construção Social da Realidade teligibilidade destas declarações é que as coisas existem independentemente das representações humanas. Consequentemente, quando tentamos nos comunicar, a fim de alcançar uma compreensão normal do outro através destes enunciados, devemos pressupor o realismo externo" (SEARLE, 1998, p. 135, grifo do autor).

eEm resumo, a comunicação, na medida em que depende sempre dos atos de fala, pressupõe a realidade. Mais precisamente, os seres humanos, quando se envolvem em uma relação de comunicação, executando atos de fala, não podem deixar de presumir que existe um mundo independente. Apesar de Searle não o afirmar com todas as letras, isto é verdade, mais especificamente ainda no caso deste tipo de comunicação feita por meio de atos de fala assertivos.

$\mathrm{Na}$ verdade, é principalmente para os atos cuja função é representar um estado de coisas que surge como condição de inteligibilidade a existência da situação. Em outras palavras, o pressuposto realista aplica-se essencialmente para as diferentes práticas de comunicação informativa, incluindo o Jornalismo, na medida em que se aplica a informação a priori. Afinal, é a mesma razão, a da informação a priori, que liga o Jornalismo à realidade e à verdade.

Em sua defesa do realismo, Searle também ataca igualmente a frente do construtivismo social ${ }^{12}$ ao elaborar uma variável de seu argumento transcendental que retorna a um aspecto desenvolvido na rejeição ao argumento da relatividade conceitual. Segundo ele, é impossível sustentar que toda a realidade é resultado de uma construção social, simplesmente porque uma realidade socialmente construída implica a existência de uma realidade que, 
por sua vez, não foi construída: “(...) uma realidade socialmente construída pressupõe uma realidade independente de todas as representações sociais, pois esta precisa de algo a partir do que construir a construção" (1998, p. 143). Assim como a possibilidade de compreender a mesma realidade por diferentes sistemas de representação implica o reconhecimento desta realidade, a realidade construída socialmente implica o reconhecimento de uma realidade não construída e, portanto, dada.

É possível especificar para o Jornalismo esta relação entre uma realidade construída e uma não construída? Eu busquei em outro trabalho (GAUTHIER, 2004) lançar as bases de uma análise realista da construção jornalística que estabelece sucessivamente: 1) Que as notícias são objetos construídos; 2) Que elas tratam, contudo, os fatos que lhes são anteriores que eu chamo de "fatos jornalísticos" (cujos principais tipos são parte de uma longa série de distinções entre fatos não intencionais e fatos intencionais, entre fatos físicos e fatos mentais não intencionais, entre fatos não funcionais e fatos funcionais, entre fatos não agentivos e fatos agentivos, entre fatos não institucionais e fatos institucionais e entre fatos não linguísticos e fatos linguísticos); 3) Que os fatos jornalísticos são ou fatos brutos ou, mais frequentemente, fatos sociais, portanto são também construídos; 4) Que os fatos sociais são construídos a partir de fatos brutos, muito frequentemente por interação (isto é, através da construção de um fato a partir de um fato em si construído); 5) Que as notícias, por consequência, são sempre construídas a partir, em última instância, de fatos brutos que eu chamo de "fatos jornalísticos brutos" (em que os principais são fenômenos naturais, fatos mentais não intencionais acidentes humanos, ações pontuais, comportamentos contínuos, tendências, inclinações e outras disposições, bem como qualquer manifestação verbal).

\section{Conclusão}

A informação a priori pressupõe que o Jornalismo tem por função a produção de asserções verdadeiras, cuja função pressuposta em si é a que diz respeito a uma realidade bruta independente. A relação do Jornalismo com a verdade reside na sua relação com a realidade.

O realismo jornalístico, constituído desta dupla relação com a verdade e com a realidade, vai de encontro, como exposto aqui, ao construtivismo segundo o qual o Jornalismo não provém de uma realidade dada e não busca a verdade. Este realismo não nega, evidentemente, que o Jornalismo seja uma construção. Propõe simplesmente que o reconhecimento da natureza construtivista do Jornalismo não implique a rejeição da existência de uma realidade bruta e nem da busca pela verdade. Estipula que a construção jornalística é feita a partir de uma realidade que lhe é anterior e que, visto que esta tem como objetivo reportar a realidade, que vise também à verdade.

$\mathrm{O}$ realismo não nega que o Jornalismo seja uma construção; ele pretende, pelo contrário, dar conta de maneira adequada desta construção.

\section{Referências bibliográficas}

ALSTON, William P. Realism \& Antirealism; Ithaca: London, Cornell University Press, 2002. 
DELFORCE, Bernard. La responsabilité sociale du journaliste - donner du sens, in : Les Cahiers du journalisme, $n^{\circ} 2$, pp.16-32, 1996.

DEMMETT, Michael. The Logical Basis of Metaphysics. Cambridge: Harvard University Press, 1991.

. Truth and Other Enigmas. Cambridge: Harvard University Press, 1978.

DERVILLE, Grégory. Le journaliste et ses contraintes. In : Les Cahiers du journalisme, n6, pp.152-177, 1999.

GAUTHIER et al. La réalité du journalisme, Communication, 2004b

GAUTHIER, Gilles, Les problèmes du constructivisme en journalisme, Communication et Langage, à paraître, 2004a.

. Critique du constructivisme en communication, in : Questions de communication, $n^{\circ} 3$, pp.185-198, 2003.

. In defense of a Supposedly Outdated Notion: The Range of Application of Journalistic Objectivity, in: Canadian Journal of Communication, vol.18, n4, pp. 497-505, 1993.

La mise en cause de l'objectivité journalistique. In: Communication, vol.12, $\mathrm{n}^{\circ} 2$, pp.81-115, 1991.

PUTNAM, Hilary. Realism with a Human Face. Cambridge, Harvard University Press, 1990

. The Many Faces of Realism. La Salle, Ill., Open Court., 1987.

. Reason, Truth, and History. Cambridge: Cambridge University Press, 1981.

. Meaning and the Moral Sciences. London: Routledge \& Kegan Paul, 1978.

RORTY, Richard. Objectivity, Relativism, and Truth. Cambridge: Cambridge University Press, 1991.

Press, 1979.

Philosophy and the Mirror of Nature. Princeton: Princeton University

SEARLE, John. R. Mind, Language and Society - Philosophy in the Real World. New York: Basic Books, 1998.

The construction of social reality. New York: Free Press, 1995. Traduction française: La construction de la réalité sociale, Paris, Gallimard, 1998.

. A Taxonomy of Illocutionary Acts - Expression and Meaning. Cambridge:

Cambridge University Press, 1979, pp.1-29.

Estudos em Jornalismo e Mídia está sob a licença Creative Commons 2.5 